\title{
Cognitive and Constructivist Perspective of IT Based Education
}

\author{
Wojciech Walat ${ }^{1}$ \\ ${ }^{1}$ Institute of Technology, University of Rzeszow, Poland \\ Correspondence: Wojciech Walat, Institute of Technology, University of Rzeszow, Rejtana Street 16A, 35-959 \\ Rzeszow, Poland. E-mail: walat@univ.rzeszow.pl
}

\author{
Received: September 5, 2012 Accepted: January 12, 2013 Online Published: February 20, 2013 \\ doi:10.5539/cis.v6n2p9 URL: http://dx.doi.org/10.5539/cis.v6n2p9
}

\begin{abstract}
This article presents research studies regarding the definition of the genesis and determinants of ICT development in the context of behavioural, humanistic and cognitive theories of education. It explains the phenomena which are connected with their application in didactic processes. The research methodology used is based on the review of literature of the subject and some studies performed previously. The effect of the studies relies on proposing a kind of meta-programming in didactics, using the achievements of various kinds of didactic programming based on computer systems and ICT.
\end{abstract}

Keywords: cognitive and constructivist learning theory, didactic meta-programming, hypermedia, multimedia, ICT in education

\section{Introduction}

Informatisation of didactic processes is the reality meaning that schooling is connected with gaining information (from various sources) by students controlled by the tasks assigned to teachers, information processing (solving tasks in accordance with fixed patterns-procedures as well as developing own manners of solutions) and providing new information (presenting obtained results). Such a didactic process requires, at the beginning, discussing the evolution of psychodidactic theories of education from mechanistic behaviourism based on the reactivity of a human being through humanistic theories assuming the existence of natural aiming of a human being at self-fulfilment as well as exceeding own and environment limitations - an individual developing this subject-based humanity and up to cognitive and constructivist theories emphasising the role of subject-based activity and self-organisation of the human mind.

In recent days, there is a need for reorientation of the didactic system from the viewpoint of present achievements of information theories, level of development of multi- and hyper multimedia and hypertext, in particular. The flood of information causes that it is necessary to find ways for building an intelligent didactic system which is capable to reorganise considering the psychophysical properties of a student and being, at the same time, easily controlled by the teacher (Różewski, Kusztina, Tadeusiewicz, \& Zaikin, 2011). Moreover, in the educating environment of a child (student) there is a language of various media: film, television, advertising, radio or computer networks. The verbal transmission human-human (parent-child, educator-child) is completed (and is often skipped) for the benefit of the transmission: film-child, show-child, advertisement-child, website-child. These are not only new forms of providing information and checking its characteristic messages but also there is a particular manner of perceiving the world, thinking order as well as remembered and recalled images. That is why the language of describing a didactic process is changing gradually by excluding the characteristic feature for the languages of particular kinds of media that surround a student.

Including audiovisual or multimedia didactic means that learning and teaching processes result not only from a conviction of a necessity of their implementation by means of the requirements resulting from the principle of using visual methods in teaching, though, it is also caused by the aims assumed by contemporary school and undertaken by the IT society (Rychen \& Salganik, 2003).

In order to achieve such educational aims such as: receipt and ordering information, its storage and passing, requires proficiency in using IT - filtrating incoming information and building from these obtained portions a cohesive image of the world: social, technical and natural etc. Thus, it is deemed important to define and create a hierarchal set of IT competences whose mastering will be concurrently the basis for building the system of students' achievements as educational results. 
The place of media education within the system of general education is its dispersion, which means, that it is not a good solution to separate school subject nor special kinds of activities for implementation of their aims. This is a great chance to include this field of education on the basis of an irreducible cognitive and activity component for representative fields of general education. It is about a multimedia (hypermedia) didactic strategy.

Didactic programmes, both for teachers and students are built on the basis of the hypertext technology (eliminating "smog" and "fog") information and on the didactic basis ordering learning and teaching. There is an extremely important assumption that media cannot be accommodated in a free manner (Różewski, Kusztina, Tadeusiewicz, \& Zaikin, 2011). They should be designed and implemented in form of the system of didactic materials to the learning and teaching process.

Introduction to the didactic processes of self-organising curricula based on the achievements of general didactics and artificial intelligence and expert systems, requires conducting studies aimed at explaining phenomena connected with teaching students in a new educational reality.

The notion of didactic meta-programming was introduced out of the necessity of "going beyond" stable, traditionally shaped manners of didactic programming. Pursuant to the new understanding of the prefix 'meta-' meaning: beyond, after, over, together, among, according to - there is a kind of succession or variability of something. In IT, meta-programming, there is a technique by means of which a given program may change or create the code of other programs during their time of operation. Thus, a didactic meta-program is a program within the framework of which, there are all programs for a student and teacher, creating a cohesive educational space depending on the needs and possibilities for learners and teachers. It is possible thanks to the use of hypermedia (self-organising) didactic programs.

\section{Behaviourist Theories of Learning - Primary Sources of Didactic Programming}

Behaviourism in the studies on learning was strongly supported by psychologists such as, Thorndike (1990), Watson (1990), Pavlov (1951) and Skinner (1960) or Gagne, Briggs and Wager (1992), who assumed the basis for explaining the processes of learning as the analysis of environmental factors causing certain behaviour of a human being. The basis for this theory relates to two general assumptions. Firstly, learning may be explained in the categories of processes which are observable in the classical conditions (defining the relations between stimulant occurrences in their environment) and causative (causative behaviours created by an organism which influence the environment and changing it). Secondly, behaviours of all organisms may be described by means of these general laws of learning. In the criticism of the opinions of behaviourists, it was indicated, that learning is not only determined by environmental factors but also by biological factors (genetic facilitation of a human being) and cognitive ones which rely on learning by means of observing rules and learning by insight (Zimbardo, 1999). Contemporarily conducted studies (Gagne, 1992) on determinants and learning provide that many organisms beyond mastering concrete reactions and associations between concrete occurrences as well as abstract, symbolic associations, general patterns of reactions, rules as well as are also able to learn and understand the meaning of links connecting stimuli with reactions. Scientists from various disciplines use such procedures and paradigms in studies on memory, expressions, perception, language as well as structure and functioning of the brain.

The American psychologist Watson (1990) as the first one, made an attempt to "materialise" thinking - releasing it from the mystique indefinite in which it has been entangled since the turn of 19th and 20th introspection. This thinking has been connected strictly with verbal and motoric reactions in an identity manner. In every kind of thinking, there are three groups of reactions: motoric, verbal and emotional. Depending on the kind of these reactions, we may talk about verbal, motoric and emotional thinking. He also claimed that the subject of psychology cannot be the conscious nor motivation but possibly observable behaviours - reply to a given stimulus.

In behaviourist theories of learning, the basic mechanism of learning is emphasised by combining various elements, those already remembered on the basis of similarities, closeness as well as behaviourism between external situations and human behaviours. The convergence (within time) of acquired elements is sufficient to create similarities and it decides on so called strengthening various forms of applied awards and punishments. Thorndike (1990) in the theory known connectionism claimed that learning is the process of creating new associations (connections) between the stimulus and reactions. He formulated, on basic laws of learning: the effect law - connections between the stimulus and reactions are strengthened by gaining satisfaction (awards) as well as exercise law - repeating the learned reaction strengthens the connections between them. These assumptions made it possible for a present concept of programmed learning begun by Skinner (1960) relying on 
application of the following rules in learning: small steps in dividing learning material, activating students by filling gaps in a text, immediate strengthening, individualisation of pace and content (see Figure 1).

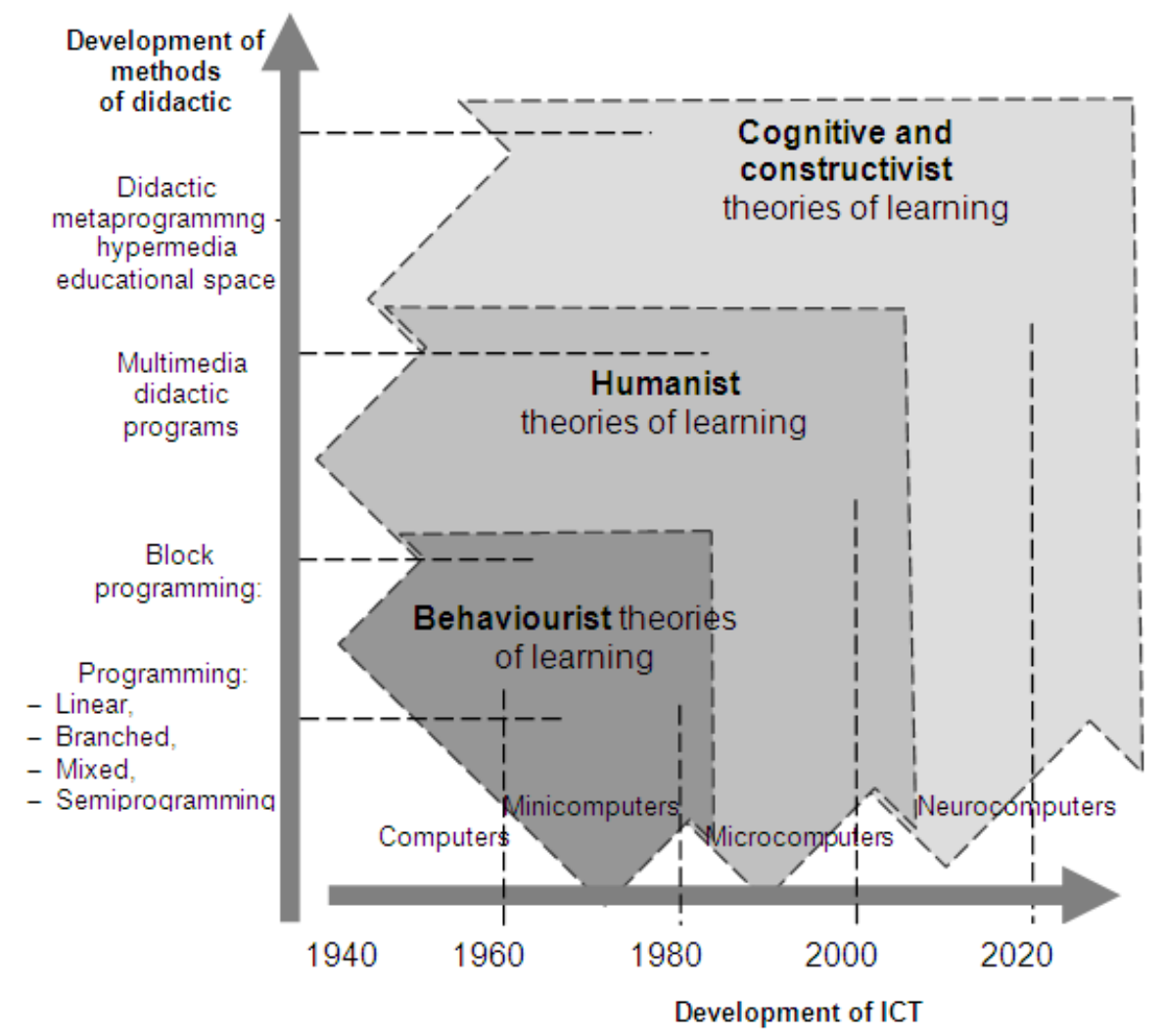

Figure 1. Development of psychological and pedagogical conceptions of learning in the context of developing the methods of didactic programming and ICT (Walat, 2007; 2011)

On the basis of behaviourism, the theory of social cognition has been developed by Bandura and Walters (1963), explaining learning social conduct in the scope of application of moral values, cooperation, aggression. The basis for this theory relies on the modelling mechanism being learnt by observation and then following other people: in the human mind, the behaviours are preserved in form of images and symbolic representations (e.g. children and teenagers follow behaviours, both positive and negative, depending on the features of the followed persons). Learning by modelling and copying refers both to education and didactics.

This approach to the didactic process is not new in didactics. In the 1960s and 1970s there were performed extended studies on didactic programming not only in Poland (Kupisiewicz, 1966; Kruszewski, 1972; Denek, 1984) but also in many countries in the world i.a. in England (Austwick, 1964), USA (Skinner, 1960; Pressey, 1961; Crowder, 1961) and obviously along with various psychological and philosophical conceptions of a human, which constitute the basis for programming didactic processes. The common feature of these programs, which could not be overcome was that each kind of didactic programming lead to objectivisation of a learner. Sooner or later, the learner was in a situation of an incapacitated link within the program network.

Contemporary tendencies of behavioural psychology (neobehaviourism) rely on the attempt of combining this learning concept with cognitive psychology by including it in the area of education interactions of thinking processes (internal factors) directed at self-opinions, self-directing and self-verbalisation etc.

In the trends of studies on learning are works of R. N. Gagne who developed five kinds of learning (intellectual skills, cognitive strategies, verbal information, practical skills and attitudes) and defined three kinds of events during the act of learning. 


\section{Humanistic Theories of Learning - Multimedia Didactic Programming}

Humanistic theories of learning arose from humanistic psychology assuming that (Kozielecki, 1995):

1) Human is the unique entirety of two subsystems - psychological and biological;

2) Basic property of a human nature is the limited development limited not only by external conditions but also internal factors;

3) Main causative force of human actions is aiming at self-fulfilment (to activate potential chances transgression); a human being is not only interested in the product but also in creative experiences;

4) Nature of a human being shows that he is good and his actions are constructive and positive; if a human being acts destructively, then the reality in certain conditions does not allow him to act constructively (he does not see any way out);

5) Behaviour of a human being is determined by presence, by present experiences, by what happens here and now, how a human being, in a given moment, perceives himself and the world, decides on the course of the self-fulfilment process.

One of the main propagators of the humanistic theory of learning Rogers (1969) formulated the following regularities of learning:

- Children have a natural desire for learning;

- Learning brings the best and most durable results if it is made in the environment free of threats. The process of learning is strengthened if learners may try, experiment, make mistakes without facing critics and laughing. Self-learning roots the sense of independence and reliability in learners;

- Learning is the most significant and extended if it is self-initiated and if it engages both feelings and the mind of a learner (so called whole person learning). The planned content and application of various technologies is less important, more important is accommodating the learning process to the learners' feelings and quality of interactions between students and teachers;

- Most useful is learning how to organise the process of self-learning. The sign of our times means a rapid pace of changes in various walks of life. It means that knowledge undergoes constant strengthening and modifications. A human being learns the best in the changing environment.

On the basis of humanistic psychology, there is personality pedagogy in which the main task of an educator-teacher is to build "own me" in a learner. A teacher starts his work with understanding a learner, seeing the world with the eyes of the student; the teacher recognises what the learner thinks about himself, his world and certain emotions. Looking into learner's motives, it is possible to change the behaviour of an individual. It means that the basic theory makes notions become the conduct of a human being. That is why, even the most meticulously presented and organised content by the teacher is not sufficient, the craft of teaching relies on how to help students to extract personal meaning of presented content.

The ideas included in humanistic theories of learning influenced the dissemination of multimedia education which relies on the fact that multi-code learning influences many senses of a learner as well as multisided activation. A human being learns not only by means of the system of verbal signs but also graphical, image or sound ones. Thanks to microcomputers, it was possible to create a multimedia message which combines two perceptive channels, it is possible to obtain high results in the teaching-learning process.

Multimedia and hypermultimedia didactic programs change memories and mastering of the material in an interesting navigation throughout the enriched material and interesting educational games. This causes that the newly presented material seems to be more interesting for learners and it encourages them to learn. Interactiveness is a very important feature of hypermedia programs. A learner may accommodate presentation to his needs, assess which messages are known and which shall be learned in-depth. He takes decisions what to do at a given moment. This causes that a learner cannot be passive but shows some activity. Interactiveness of multimedia causes that a learner is aware which actions are taken within a program depending on his choice and a manner of directing the process of learning.

A contemporary rapid growth in the amount of information forces teachers to obtain newer and newer tools. Knowledge passed to students is aimed at preparing them for life in the contemporary world which is defined as the world of computers, robots and lasers. That is why it is desired that a learner could acquire not only writing, reading, numeracy but also master computer skills. 
School is a place where technology should enter at the very beginning. So as the didactic process shall not be based on one method of teaching, but it is necessary to use various didactic means, both traditional and modern ones. I believe that the basic condition for multimedia education, providing properly high results is that the media were applied in a free manner. Designing and introducing integrated multimedia packets to the didactic process may become an irreducible component (Lib, 2008).

Using media and multimedia, the learner may know himself, other people and the world, introduces new experiences, develops personality, cognitive, emotional and motivational spheres. Attractive form of passing knowledge makes it eagerly used by children as a source of gaining knowledge and learning.

Nowadays, there are certain tasks of multimedia in education:

- Passing and processing information,

- Presentation of didactic content,

- Visualisation of phenomena, processes,

- Easing and increasing attractiveness of communication between humans and computers,

- Didactic games and plays as well as entertainment,

- Extending access to information.

While selecting presentation media which shall be used in playing HPD, the following determinants are considered:

- Availability, handiness, easy to set up,

- Quality of hardware and operation materials,

- Efficiency in passing information.

Educational facilitation of computers (ICT) results from their constitutional features, thus they allow sending, processing and storing unimaginable pieces of information. Apart from the aforementioned, there are specific determinants such as (2004):

- Polysensory determinants i.e. influencing many senses of a human by means of one complex message;

- Multimedia i.e. possibility of combining hardware and software along with many media and their functions;

- Interactive i.e. ability to dialogue among humans and computers, providing a subject sense of activities for a learner;

- Simulation i.e. a possibility of imitating real phenomena, processes or devices;

- Communicativeness i.e. capability of providing, by means of a network, visual, sound or symbolic connection with the other person (by means of another computer);

- Virtualisation i.e. capability of creating a fictional reality, called virtual reality or cyberspace;

- Globalisation i.e. access to information in a synchronous or asynchronous mode on any place in the earth;

- Mobility i.e. access to virtual and real space from any place and any moment.

Combining the development of microcomputers with multimedia computer programmes (Figure 1) constitutes the essence of using ICT in humanistic theories of learning. It leads to be mobile in a virtual world i.e. in the effect, separating a learner from the acquired reality - leads to feigned learning. These problems were broadly tackled by Mc Luhan (1975) and Kherckhove (2001).

\section{Cognitive and Constructivist Theories of Learning - Didactic Meta-Programming}

Few years after the end of the Second World War, in 1950s, there were many significant works on psychological concepts of a human based on the assumptions of cybernetics as the science of control. The accomplishments of Wiener (1950), Bartalanffy (1984) and Ashby (1963) resulted in including such notions as: information, feedback, black box, control system as well as other information and control theories into psychology. However, the basic notion remained was information comprehended in a quantitive form - as the measure to reduce uncertainty as well as qualitative - as the content with a specific meaning i.e. representation of a certain fragment of reality. The scope of works and studies performed by cybernetics theoreticians were processes of control i.e. processing information into operations modifying states of a given system. The effect relied on paying special attention at information processes of an individual, self-regulation, control and correcting measures mechanisms with regard to certain standards as the indispensible conditions for regulating processes. The turning point in 
thinking on mechanisms of human behaviour was the work of Neissera: Cognitive psychology (1967). The author proposed the conceptions of the active mind of an individual in the scope of cognitive processes (e.g. memory, attention, selection of information, processing information, solving problems), being contrary to the binding passive conceptions (associating). Cognitive psychology was treated as the science on functioning of the mind.

For the analysis performed in the article, interesting is a cybernetic base for cognition which was created by Berlyne (1969), in the scope of cognitive psychology mentioned previously by Neisser and Chomsky (1968), in the scope of social psychology mentioned by Lewin (1951), Kelly (1955), Festinger (1957), Heider (1958), Kelley (1971). Since the end of 1950s, the cognitive direction of psychological studies was becoming stronger and stronger, reaching its peak in 1970s. At present, similarly equal direction of studies, however, conducted in a multidimensional way, is hard to mention by all acknowledged psychologists.

Kelly may include the following assumptions of cognitive psychology as a range of specific applications (Lukaszewicz, 2000):

1) People anticipate events, thanks to which, construct the replicas of the events, their images or reflections (assumptions of constructing); these replicas have been called personal constructs;

2) People differ in possessed constructs of events (assumption on individual differences);

3) Each individual shapes anticipating processes, however, the cognitive system includes ordered relations between constructs (organisation assumptions);

4) Cognitive system of an individual is composed of a limited number of dichotomous constructs (assumption of dichotomy);

5) Among dichotomous constructs, people choose this possibility which has a greater usability of the entire cognitive system (assumption of selection);

6) Personal construct is needed for anticipating only a given scope of events (assumption of the application scope);

7) Cognitive system is changing as people gradually create other images of events (experience assumption);

8) Variability in the cognitive system is limited, what results from the limited capability of creating constructs to accept discrepancies (modulation assumption);

9) People may use many constructs which are not agreed to each other (fragmentation assumption);

10) If two persons refer to a similar system of experiences, it may be anticipated that their behaviour will be similar (dividing assumption);

11) If a person influences creating a cognitive system of another people, it may cause emerging social behaviours in this other person (socialisation assumption).

The common feature of the aforementioned assumptions formulated by various directions in cognitive psychology, is that gaining experience relies on creating dichotomous (white and black, small and big, light and dark) representations of the reality. These representations have a dynamic character (experience is gained and internal compliance is greater). The content of these representations (constructs) results in human's behaviour. Generally, it may be useful to observe psychological assumptions of cognitivism:

1) An individual is not a reactive system, to the contrary - is an active system, independently and actively seeking information, collecting experience, building experience in their cognitive system. It may be claimed that an individual is not an active player who formulates hypotheses, collecting information, confirming or rejecting their expectations. This is a concept of a naive theoretician, naive researcher and thinker (Meadows, 1995).

2) Experience does not constitute stable data but also undergoes constant process of integration, generalisations; significance of particular elements is modified by the context in which they function (Nosal, 1990).

3) Human experience is a tool for a cognitive control over the environment and over themselves and used for anticipation, constructing expectations, action plans, formulating aspirations, causal explanation of events, understanding own behaviours and others (Bandura, 1969; Charms, 1969). 
4) The experience system is not a strictly logical structure. It is constructed on many ways and the loftiness of described occurrences, their repeatability (Łukaszewski, 1974; Reykowski \& Kochańska, 1980), order etc. may decide on the content of the cognitive system and the manner of its organisation (Rosch, 1973).

5) The system of experiences is not only a complex representation of reality. It undergoes constant changes, as a result of which there are images of other states of things: projects, visions, aims, ideals etc.

6) In the cognitive system, there is an internal affective and motivating mechanism that triggers a given behaviour. This mechanism is - generally speaking - desire to avoid discrepancies and aiming at compliance within a cognitive system (Abelson, 1968).

7) Human actions have a rational character, however, the notion of rationalism has changed many times. It has evolved from the conviction that human actions and decisions meet formal requirements, normative models based on classical logics, to convictions on the individual character of human rationalism, referring to an individual and group criterion of sufficiency in actions (Lewicka, 1993).

8) A normal (typical) state in each human is desire for constant enriching the structure of experience as well as aiming at eliminating unnecessary (excessive) diversity. Aiming at equilibrium between diversity and extending information resources is a basic determinant of a schematic structure of human experience.

In cognitive theories of learning, the basic thesis that any element may be remembered, if it has been included in a much greater, existing entirety - human is a separate and creative subject, who is capable of creating themselves (their competences, motivations and emotional maturity). Kozielecki (1995) writes that a human being is a system processing information and his behaviour, i.e. learning depends on the information flowing from the external world and internal information i.e. subjective cognitive structures. As the time of learning and manipulation of strengths in form of awards and punishments played a basic role in association theories, in cognitive theories, the basic meaning has a structure being a program regulating behaviour of a human, determining his cognitive, creative and action-based activity. The example of the classical cognitive theory - structural - is the theory of assimilation and accommodation by Piaget (1966).

The significance of knowledge and cognitive processes was emphasised in the works by Bruner (1964): a learner is capable to generate new knowledge and go beyond obtained information. Kozielecki (1995) defined the human mind as the reproductive and generative medium, a human being not only assimilates external information but can also create new ones.

On the basis of cognitive psychology the concept of constructivism has emerged, by means of excluding the results of research by Piaget, Wygotski and Brunera, achievements of artificial intelligence including: neuron networks, expert systems and databases. In constructivism, it is assumed that knowledge is a construction of human mind, which comes into being as a result of own and diversified activity. A human being not only acquires fixed knowledge (as a product) provided by others, but also constructs their own system of knowledge by undertaking various kinds of activity:

- Verbal (asking questions and formulating answers),

- Practical (conducting experiences and formulating conclusions and hypotheses),

- Intellectual (starting the processes and analysis and synthesis),

- Sensory (directed at noticing and remembering imaginary schemes),

- Receptive (listening and selection of acquired messages),

- Emotional (experiencing and dealing with stress).

In these situations, teachers play a role of a "mediator" - agent helping students to choose proper strategies of learning, manners of solving problems and self-acquiring of knowledge. In the role, the teacher and students may be supported by didactic (hypermedia) computer programmes which shall include the best didactic strategy of learning in a given situation, assisting a learner in his research approach to the world: observing phenomena, formulating hypotheses, conducting experiments and simulations and drawing conclusions These actions are very often named constructionism relying on creating new structures of knowledge which may help others (students) not only remember a given fragment of reality but also provide their own subjective meaning. To a great extent, it is a natural desire of a human being: participants take notes during lectures, speeches. Even if they do not use the notes any more - only during the lecture - by means of taking notes, there is processing of provided information in a notion construct. 
While creating notion constructs it is necessary to self-organise didactic programmes created on the basis of didactic meta-programming, according to individual psycho-physical properties of students. It is possible thanks to dynamic development of IT in the scope of hardware and software (including AI).

\section{Conclusion}

The analysis conducted in the article presents the complex (complimentary) aspect of theory of learning and teaching in designing computer didactic programmes. The attempt to answer a question: whether on the basis of the aforementioned psychological and pedagogical analyses of theory of learning it is possible to claim explicitly which one is the best? Seeking a homogenous theory regardless of its multidimensional character of human psychics is doomed to be failure. All psychological concepts of a human emphasise one or several dimensions of its essence.

For further analyses on seeking optimal solutions in the scope of designing and optimising computer didactic programs, their didactic and methodological complementary is assumed, relying on mutual complement of particular concepts as well as methods and forms of organising didactic processes. It is observed in the richness of aims and content of education as well as differentiation in properties and experiences of students having a significant meaning in the processes of learning.

\section{References}

Abelson, R. P. (1968). Theories of cognitive consistency: A source book. Chicago: Rand, McNally.

Ashby, W. R. (1963). Introduction to cybernetics. Warszawa: PWN (Polish ed.).

Austwick, K. (1964). Teaching Machines and Programming. Oxford: Pergamon Press.

Bandura, A. (1969). Principles of behavior modification. New York: Holt.

Bandura, A., \& Walters, R. H. (1963). Social learning and personality development. New York: Holt, Rinehart and Winston.

Bartalanffy von, L. (1984). General theory of systems. Basics, development, application. PWN, Warszawa (Polish ed.).

Berlyne, D. E. (1969). Structure and direction of thinking. PWN, Warszawa (Polish ed.).

Bruner, J. (1964). Education process. Warszawa: PWN (Polish ed.).

Chomsky, N. (1968). Language and mind. New York: Harcourt Brace Jovanovich.

Crowder, N. A. (1961). Intrinsic and Extrinsic Programming. In Programmed Learning and Computer-Based Instruction, J. W. Coulson (Ed.). New York, London: J. Wiley and Sons, Inc.

De Charms, R. (1969). Personal causation. New York: Academic Press.

Denek, K. (1984). Didactic programming in higher school. Warsaw: PWN (Polish ed.).

Festinger, L. (1957). A theory of cognitive dissonance. Evanston: IL: Row, Peterson.

Gagne, R. M., Briggs, L. J., \& Wager, W.W. (1992). Principles of didactic designing. Warszawa: WSiP (Polish ed.).

Heider, F. (1958). The psychology of interpersonal relations. New York: Wiley. Retrieved August 20, 2012, from http://www.my-ecoach.com/idtimeline/learningtheory.html

Kelley, H. H. (1971). Attribution in social interaction. Morristown NJ: General Learning Press.

Kelly, G. A. (1955). The psychology of personal constructs. New York: Norton.

Kerckhove, D. de. (2001a). Culture cover. Discovering new electronic reality. Warszawa: Nikom (Polish ed.).

Kerckhove, D. de. (2001b). Open intelligence, Birth of network society. Warszawa: Nikom (Polish ed.).

Kozielecki, J. (1995). Psychological concepts of a human. Warszawa: Żak (Polish ed.).

Kruszewski, K. (1972). Programmed teaching in the didactic system. Warszawa: PWN (Polish ed.).

Kupisiewicz, C. (1966). Programmed teaching. Warszawa: PZWS (Polish ed.).

Lewicka, M. (1993). Actor or observer. Psychological mechanisms of deviations from rationalism in common thinking. Warszawa: PTP (Polish ed.).

Lewin, K. (1951). Field theory in social science. New York: Harper \& Row.

Lib, W. (2008). Modern media in education - example of didactic movie production. Informatologia, 41(3), 210-213. 
Łukaszewicz, W. (2000). Psychological concepts of a human. In J. Strelau (Ed.), Psychology. Gdańsk: T. I, GWP (Polish ed.).

Łukaszewski, W. (1974). Personality. Structure and regulating functions. Warszawa: PWN, (Polish ed.).

Mc Luhan, M. (1975). Selection of writings. Warszawa (Polish ed.).

Meadows, S. (1995). The child as thinker: The development and acquisition of cognition in childhood. London: Routledge.

Neisser, U. (1967). Cognitive psychology. New York: Appleton-Century-Crofts.

Nosal, C. (1990). Psychological theories of the mind. Warszawa: PWN (Polish ed.).

Pawłow, I. P. (1951). Twenty years of studies on superior nerve activity in animal behaviour. Warszawa: PZWS (Polish ed.).

Piaget, J. (1966). Birth of child's intelligence. Warszawa: PWN (Polish ed.).

Pressey, S. L. (1961). Development and appraisal of devices providing immediate automatic scoring of objective tests concomitant self-instruction. In W. I. Smith \& J. W. Moore (Eds.), Programmed learning: Current trends in theory and research. New York: N. C. Inc.

Reykowski, J., \& Kochańska, G. (1980). Drafts on theory of personality. Warszawa: WP (Polish ed.).

Rogers, C. R. (1969). Freedom to learn for the 80's. Columbus, Ohio: C. E. Merill Publishing Company.

Różewski, P., Kusztina, E., Tadeusiewicz, R., \& Zaikin, O. (2011). Intelligent Open Learning Systems: Concepts, Models and Algorithms (Intelligent systems reference library). Springer-Verlag Berlin Heidelberg.

Rosch, E. (1973). On the internal structure of perceptual and semantic categories. In T. E. Moore (Ed), Cognitive development and the acquisition of language. New York: Academic Press.

Rychen, D. S., \& Salganik, L. H. (2003). Key Competencies for a Successful Life and a Well-Functioning Society. Hogrefe Publishing.

Skinner, B. F. (1960). Teaching Machines. In A. A. Lumdaine \& R. Glaser (Eds.), Teaching Machines and Programmed Learning: A Source Book. Washington: National Education Association of the US.

Tanaś, M. (2004). Didactic context of remote education. In M. Tanaś (Ed), Pedagogy@ IT means and media. Warszawa-Kraków: WSP ZNP, Oficyna Impuls (Polish ed.).

Thorndike, E. L. (1990). Learning people. Warszawa: PWN (Polish ed.).

Walat, W. (2007). Educational application of hypermedia. Rzeszów: UR (Polish ed.).

Walat, W. (2011). Didactic meta-programming as a hypermedia educational space. Journal of Technology and Information Education, 3(2), 5-9. Retrieved August 24, 2012, from http://www.jtie.upol.cz/clanky_2_2011/walat.pdf

Watson, J. B. (1990). Behaviourism. Warszawa (Polish ed.).

Wiener, N. (1950). The human use of human beings. Cambridge: MIT Press.

Zimbardo, P. G. (1999). Psychology and life. Warszawa (Polish ed.). 